\title{
Design in healthcare: the challenge of translation
}

J. WEST

\section{[AQ0] \\ [AQ4] DJonathan West ${ }^{1}$ \\ 1. Helen Hamlyn Centre for Design, Royal College of Art, London, UK}

Jonathan West is Senior Research Fellow and Reader at the Royal College of Art. 17 years' experience of design in healthcare. Managed numerous industry and public funded R\&D projects ( $£ 330 \mathrm{k}-1.5 \mathrm{~m})$. His award-winning research and innovations are used in many hospitals. His work has been published internationally in journals, books and as papers.

CONTACT Jonathan West jonathan.west@rca.ac.uk Reader in Healthcare Design, Helen Hamlyn Centre for Design, Royal College of Art, 4 Hester Rd, SW11 4AN, London, UK

\section{ABSTRACT}

This paper draws on the history of inclusive design and design for patient safety work at the Helen Hamlyn Centre for Design at the Royal College of Art to illustrate translational difficulties facing product designs developed with and initiated by clinical researchers. Three case studies are explored to outline common challenges faced by innovations in the efforts to commercialise and achieve adoption into front line use. Translational difficulties were discussed in a multidisciplinary workshop with designers, human factors, regulatory and procurement personnel. The differences between the conceptions of the design process and the process by which innovations are adopted into widespread use were explored in more detail through mapping exercises and a pilot design project.The paper uses the case studies and a workshop to draw on theory of design and models for optimising translation, with a particular focus on procurement and incremental innovation. The conclusion is a proposed methodology for optimising the inclusive design process in healthcare to produce innovations which are more likely to be adopted into front line use. The methodology involves downstream stakeholders (namely regulatory and procurement expertise) in addition to the standard front line users, building in ambition from incremental to more fundamental innovations.

Keywords: Translation ; inclusive design ; human centred design ;implementation ; commercialisation

This paper focuses on and analyses a series of projects undertaken by the Helen Hamlyn Centre for Design (HHCD) at the Royal College of Art (RCA), responding to the NHS Design for Patient Safety initiative and other healthcare briefs. It identifies strengths, weaknesses and obstacles to successful uptake and proposes a methodology to effectively address these issues.

The author has been involved in all healthcare design work at the HHCD for 15 years, from conducting sole projects to leading multidisciplinary teams. From a background in industrial design, the author's work, and that of the team, now draws on many design disciplines, spanning product, information, digital and service design. It also spans primary and secondary care, individual and community health, and physical and mental health. Though there have been real world impacts and translational successes, this paper focuses on methodological changes to achieve greater impact from the inclusive design process in healthcare.

\section{Limitations}


As the paper details the limitations and drawbacks of the approach of each case study, the author has chosen to draw only on work he was directly involved in. As such, a tentative conclusion is drawn, but further research is needed to allow a broader study of similar work in the field. The aim is to invite further discussion and case studies more broadly in the field.

\section{Introduction}

The Royal College of Art has a long tradition of stakeholder involvement and research-led design dating back to the 1960s, when Bruce Archer's work, in collaboration with the King's Fund and Nuffield Health, resulted in the King's Fund bed which was widely adopted (Boyd Davis and Gristwood 2016). Archer's work at the RCA was ground-breaking; there he established the discipline of design research, promoted evidence-based design and systems-level analysis, and design processes presaging the modern multi-disciplinary design team.

This tradition was renewed in 1991 under the DesignAge programme, which broke with top-down approaches by prioritising lifestyle consumer choice and user-led design as key to tackling challenging issues such as population ageing in affirmative and enabling ways (Coleman et al. 2007, 26). The logical outcome of this approach was the concept of Inclusive Design (Coleman 1994) that has underpinned the work of the Helen Hamlyn Centre for Design across a wide range of fields since its inception in 1999.

In 2004, the RCA's focus on design in healthcare was renewed by the Design for Patient Safety (DPS) scoping study (Clarkson et al. 2004), commissioned by the UK NHS via the National Patient Safety Agency (NPSA) in collaboration with the Design Council and with the full support of the Chief Medical Officer Liam Donaldson, a world leader in healthcare quality and safety. The study was triggered by evidence of the high rates of medical error and adverse events during hospital treatment across all major healthcare systems (de Vries et al. 2008). In response, a research team from three leading research institutions - the RCA, and the universities of Cambridge and Surreywith expertise in design, systems engineering, ergonomics and human factors, proposed a design-led, systems-based approach to improve patient safety in hospital and mobile healthcare.

The report concluded that three key factors were involved in patient safety: equipment/facilities, people/behaviour and process (Clarkson et al. 2004, 42-44). The Inclusive Design approach is to view all factors as interconnected; product design can change process and encourage people towards correct usage, and so on.

Following the report, a series of demonstration projects was initiated by the NPSA in collaboration with the HHCD. Early work included, for example, packaging design to reduce picking errors in pharmacies (Swayne 2007) and an award-winning redesign of the resuscitation trolley (West et al. 2008). The expertise and collaborative network built up during these projects led to larger scale, multi-disciplinary and multi-institutional projects such as the Engineering and Physical Sciences Research Council-funded Designing Out Medical Error (DOME) project, and a long-standing ambulance redesign programme.

\section{Front line initiated design}

Over the past 15 years, through its Research Associate Programme linking recent RCA graduates with industry, government and voluntary sector partners, the HHCD has conducted a number of projects in healthcare, ranging from product to information, service, digital and VR design. These projects focus on design innovation, begin with a fundamental design research question, and are largely clinician- or researcher-led, as opposed to commercial design projects which may start from an existing market position and have good access to commercial considerations and regulatory expertise.

As such, many of these projects can be viewed as beginning in clinical experience. We might term these projects front line initiated design: often a problem in clinical practice has been identified, and is the start point for a project, without any pre-conceived idea about what form the intervention might take, or how it might be commercialised or adopted. Often such projects are not commercially funded (at least not initially), but draw on public or charitable funds.

\section{Successes and difficulties}


This approach has triggered enthusiastic engagement from clinicians, staff and patients on the front line (who might otherwise be suspicious of commercially funded research and design), and has led to a number of international design awards (Medical Futures Innovation Awards, Design Museum 'Design of the Year' Award, Core77 Awards) and exhibitions (Royal College of Art, Design Museum, Hunterian Museum, King's Fund).

However, in the experience of the writer, this type of front line initiated design research is vulnerable to a key limitation. Although the design interventions emerging from these projects might be widely lauded, and have significant support amongst front line stakeholders and senior figures in the NHS and design industry, the transition rate to successful adoption within the healthcare services is low. This may be due to conventional factors such as: a time lag in achieving translational benefit (Morris, Wooding, and Grant 2011); the accepted attrition rate of new innovations in the marketplace; or the fact that stakeholders who are central to implementation (for example, manufacturers, marketing, business development) are less likely to view innovations emerging from such external projects as a priority over their own R\&D work. However, it may also be due to resistance within NHS purchasing systems and inertia within the adoption chain that design processes and methods employed do not adequately address.

Based on the author's experience of Inclusive Design research, and its interface with commercial and implementation efforts, some essential issues and challenges emerge consistently and are best exemplified by the following case studies. The focus here is specifically on product/device design, although there may well be parallels with other design disciplines within healthcare.

\section{Case study 1-a new resuscitation trolley}

In 2005-2007, the NPSA commissioned a collaboration between the HHCD and Imperial College to redesign the resuscitation trolley (West et al. 2008). Incident reports had pointed to potential problems inherent with the design of the trolley. The team of designers and clinicians studied the process of resuscitation, and involved doctors, nurses and resuscitation officers in a redesign. In true front line initiated fashion, the type of design output was initially unknown, as were the routes to adoption. Service, garment and information design outputs were all considered. The eventual preferred concept was indeed a new type of resuscitation trolley (Figure 1), but one that facilitated the resuscitation process by displaying equipment openly to aid access, and supporting key roles and communication between team members attending a cardiac arrest who may never have worked as a team before.

Figure 1. New design of resuscitation trolley. 


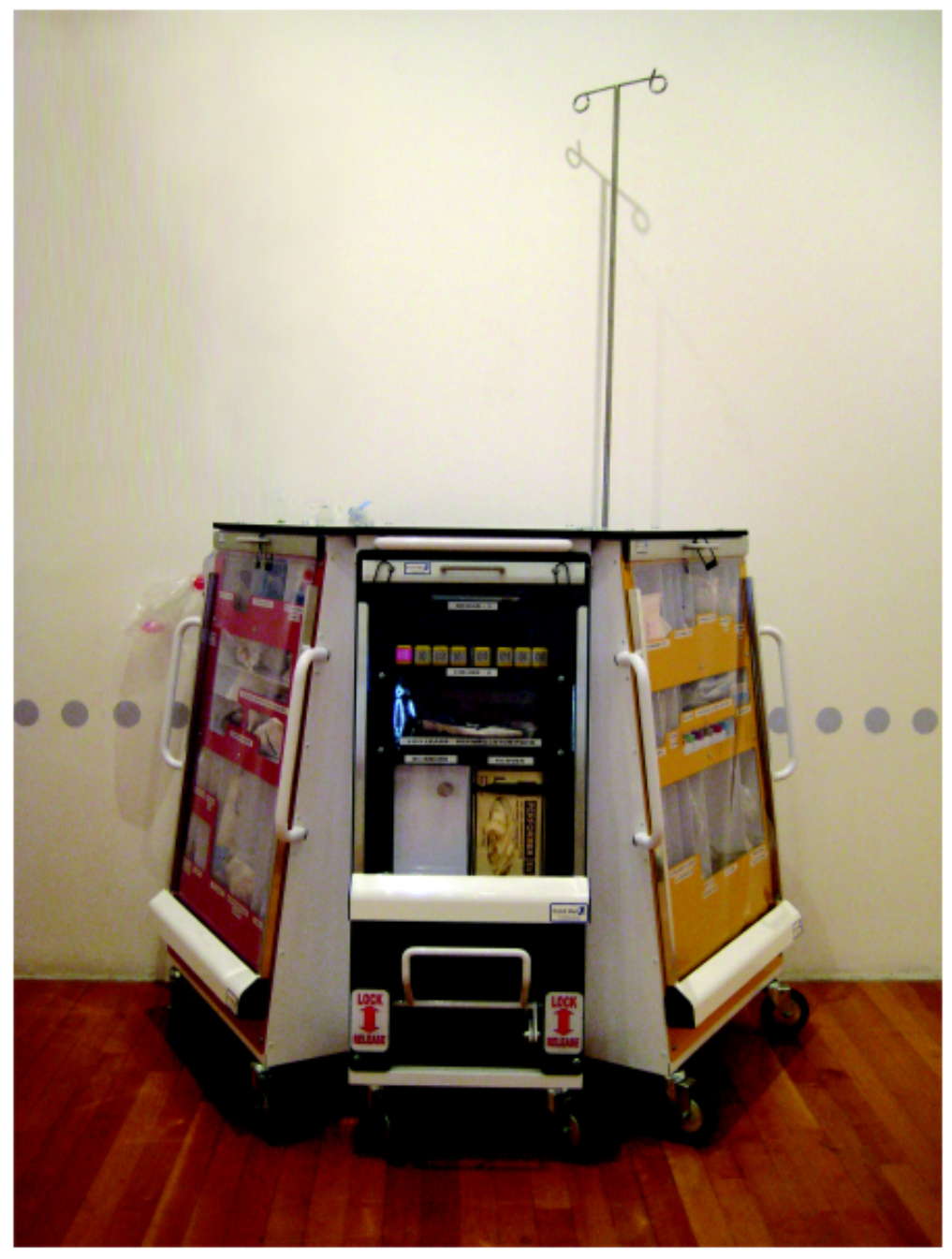

This was prototyped and trialled in simulation, leading to very positive feedback and two major design awards (Medical Future Innovation Awards 2007). The increased profile of the design helped to secure a commercial partner, and further prototypes were commissioned, used in clinical practice, and evidence was gathered to validate the design and the rationale behind it (Walker et al. 2011a, 2011b). The design was protected and licenced to a commercial partner. However, the front line impact was not widespread, as the design encountered commercial difficulties. The unit cost was higher than that of a regular resuscitation trolley, and the UK market was deemed too small (with turnover too slow) to support the higher price, despite the proven safety benefits.

\section{Case study 2-reducing cross infection in hospital}

In 2008, the HHCD worked on the 'Design Bugs Out' (DBO) project, led by the UK Design Council. The aim was to create designs for everyday ward equipment and furniture that were easier to clean, and thereby reduce the risk of cross infection and the spread of antimicrobial resistance. Two designs emerged which were commercial successes (a redesign of the commode and bedside cabinet); these notably had manufacturers present from the start of the innovation process. Amongst other concepts, the HHCD created a wipe-clean blood pressure cuff and a simple indicator placed beside cannulation sites which showed how long the cannula had been inserted for. Despite positive user response, and robust efforts to commercialise both these designs, they did not enter widespread use. The blood pressure cuff failed to make it through detailed manufacturing development due to a lack of resource. The cannula time indica- 
tor made it into use, but durability concerns hindered widespread adoption (Southampton University Hospitals NHS Trust 2011).

\section{Case study 3-a better neck brace}

In 2011-2012, the HHCD worked with Bath Institute of Medical Engineering on the redesign of a cervical collar, or neck brace (Sparke et al. 2015). Current neck braces were found to provide insufficient immobilisation of the head and neck (Smyth and Cooke 2013), and may put pressure on the carotid artery. The redesign (Figure 2), done in close collaboration with patients, clinicians and other support staff, achieved better immobilisation in trials, as well as other important benefits including reduced pressure on the carotid artery, and good airway management and imaging access to the mouth and neck. In addition, unit costs were minimised through a rigorous design for manufacture phase of the project. However, the team failed to secure a manufacturing partner, as the commercial case for adoption was not sufficiently persuasive. Even though unit cost was studiously minimised, investment in new tooling, marketing and training was underestimated, while the efficacy of neck braces themselves was challenged by clinical debate (Benger and Blackham 2009).

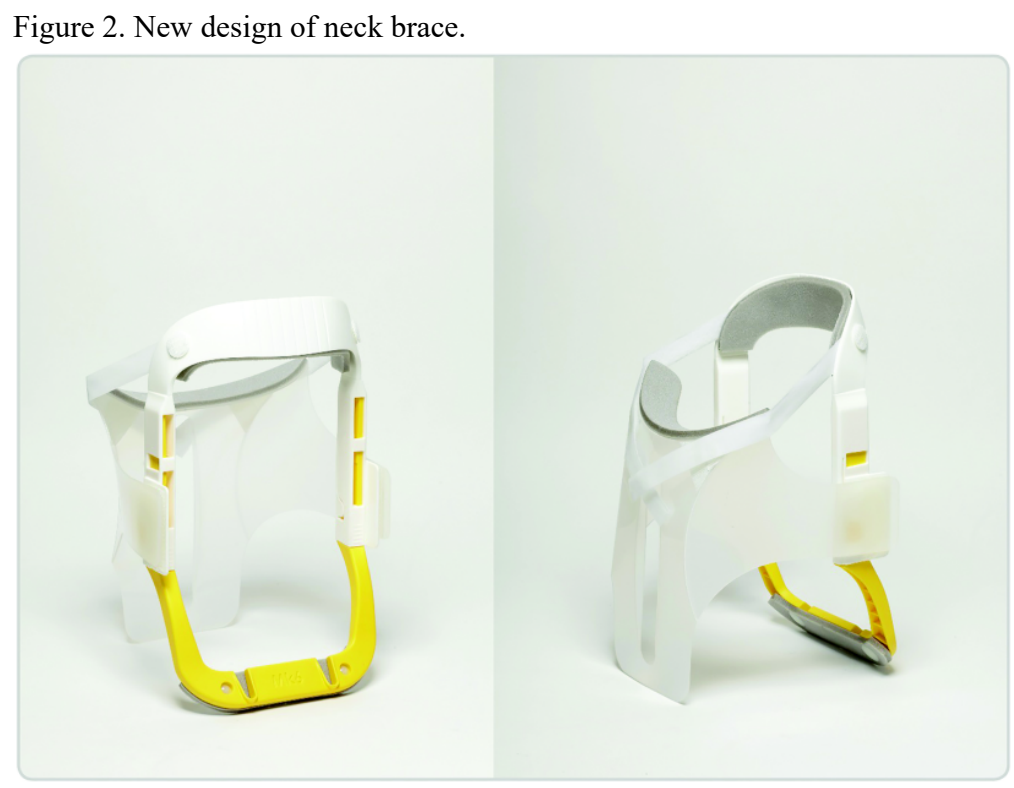

Improving all three factors highlighted by the DPS study - equipment, behaviour and process - is a considerable challenge, but essential to the goal of improving patient safety. However, the above case studies demonstrate that although taking all these factors into account can deliver high quality design solutions, a range of external, downstream challenges can hamper eventual adoption.

\section{Exploring the problem}

In light of the limitations illustrated by these case studies, the HHCD held a workshop with the British Standards Institute and the Clinical Human Factors Group in April 2019. It brought together designers, clinicians, regulatory experts, procurement and human factors expertise. These 'downstream' stakeholders provided expertise on how an innovation might comply with the relevant regulations and standards (necessary for frontline use), how it might be procured (i.e. purchased and introduced into use), and the physical and cognitive demands it might place on those using it. The aim was to explore the matter of adoption of innovation, and three short briefs (a redesign of a catheter bag tap, a three-way stopcock and a cannula) were used for the small multidisciplinary groups in the workshop to consider and thereby map out the processes of innovation and adoption. The teams discussed the process of redesign of their selected product, as well as how this might be procured and eventually adopted into front line use; some of the teams made process maps. Each team presented back, and there were many similarities in approach. An overarching map captures the thinking of the teams in the workshop (Figure 3).

Figure 3. Composite map of multidisciplinary workshop group outputs illustrating innovation and adoption processes. 


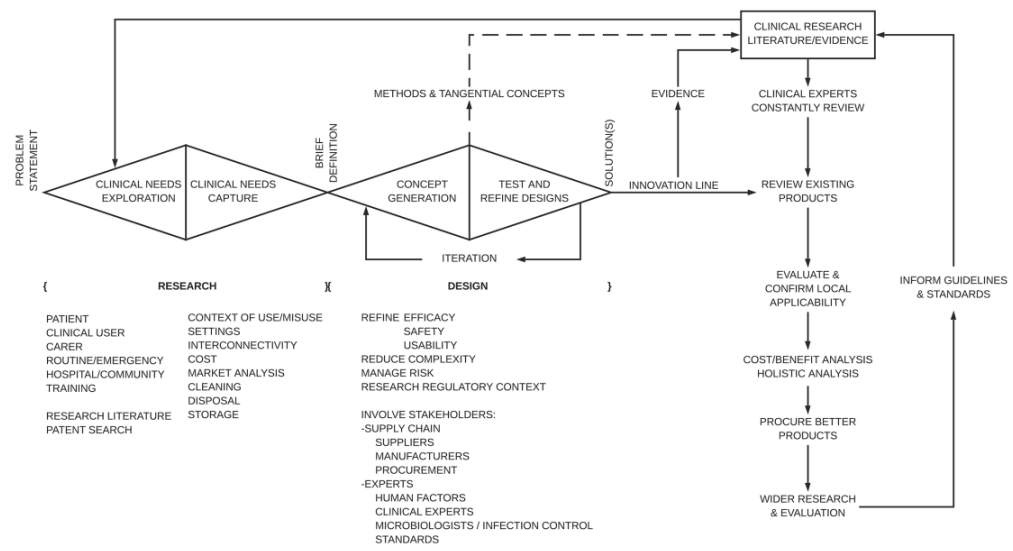

The Design Council double diamond process model (Design Council 2015) emerged as the core of the 'innovation line' in all the small group feedback, with the outputs feeding into a vertical adoption process beginning largely in clinical literature/evidence. Much of this process was not clearly understood by the designers in the workshop, and reveals that these 'downstream' implementation factors (commercial, regulatory and procurement) could be better considered during the core double diamond process in order to optimise the innovation line for adoption.

In terms of stakeholder engagement, the typical current sequence is that clinical stakeholders might identify a clinical need, design and human factors expertise would help to generate a solution, this would be trialled to gather evidence of effectiveness, the solution would undergo a refinement from regulatory and commercial stakeholders during manufacture, be bought by procurement and the design eventually adopted (Figure 4).

Figure 4. Current stakeholder engagement sequence.

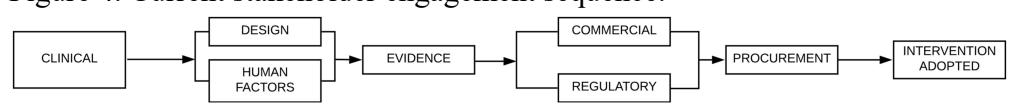

The resuscitation trolley, neck brace and DBO projects illustrate the shortcomings of this sequence. The problems were clinically well defined, evidence showed their merits, and the designs were praised from a user and ergonomic perspective. They failed at the fourth step for different reasons.

A potential restructure of the engagement with the various stakeholders may have minimised the likelihood of these problems. This would start with the identification of a clinical need, but then co-design a solution in collaboration with clinical, commercial, procurement, regulatory and human factors input, followed by validation (Figure 5). This would optimise the intervention for procurement and adoption.

Figure 5. Potential stakeholder engagement sequence.

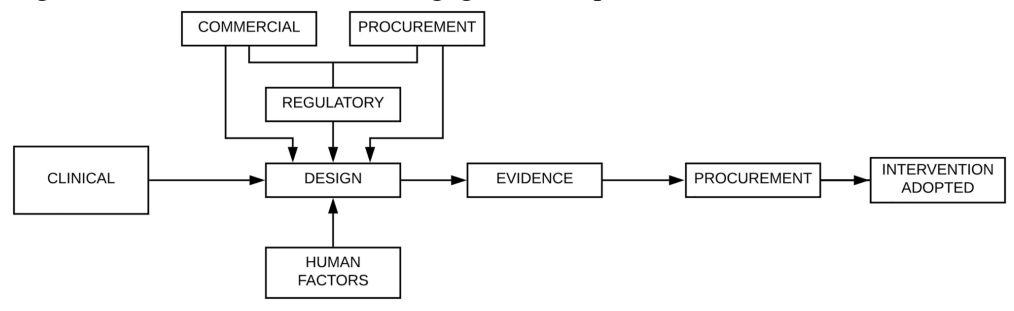

\section{Constraints and challenges}

In healthcare, Inclusive Design methodologies (e.g. University of Cambridge's Engineering Design Centre Inclusive Design toolkit 2017) have proved successful in getting designers out of the studio and involving frontline stakeholders in a meaningful way in the design process. However, the risk is that this meaningful engagement with the user is where the process stops; the downstream elements necessary for adoption are considered too late in the proc- 
ess. The conventional research and design process aims to define the correct constraints, and then deliver a solution that satisfies these constraints. These might be represented on a Venn diagram, where each circle represents a constraint, or a demand on the solution. Inclusive Design has historically been adept at defining the constraints of the needs of (for example) the patient, clinician, the clinical process, human factors and safety. A successful design must lie somewhere in the centre, and satisfy all constraints.

In Figure 6 commercial, procurement and regulatory concerns are typically not considered, but for a design to succeed it must satisfy these extra demands, as in Figure 7.

Figure 6. Overlapping constraints.

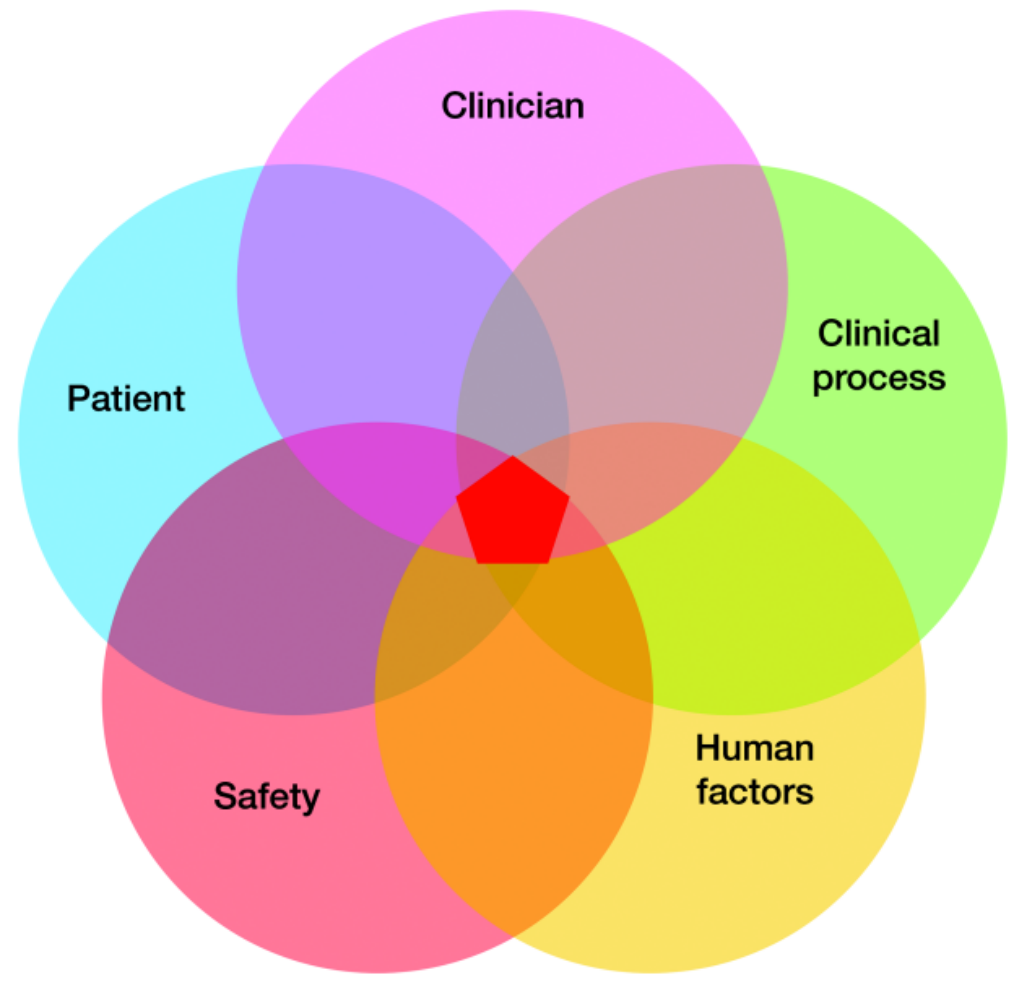

Figure 7. Further overlapping constraints.

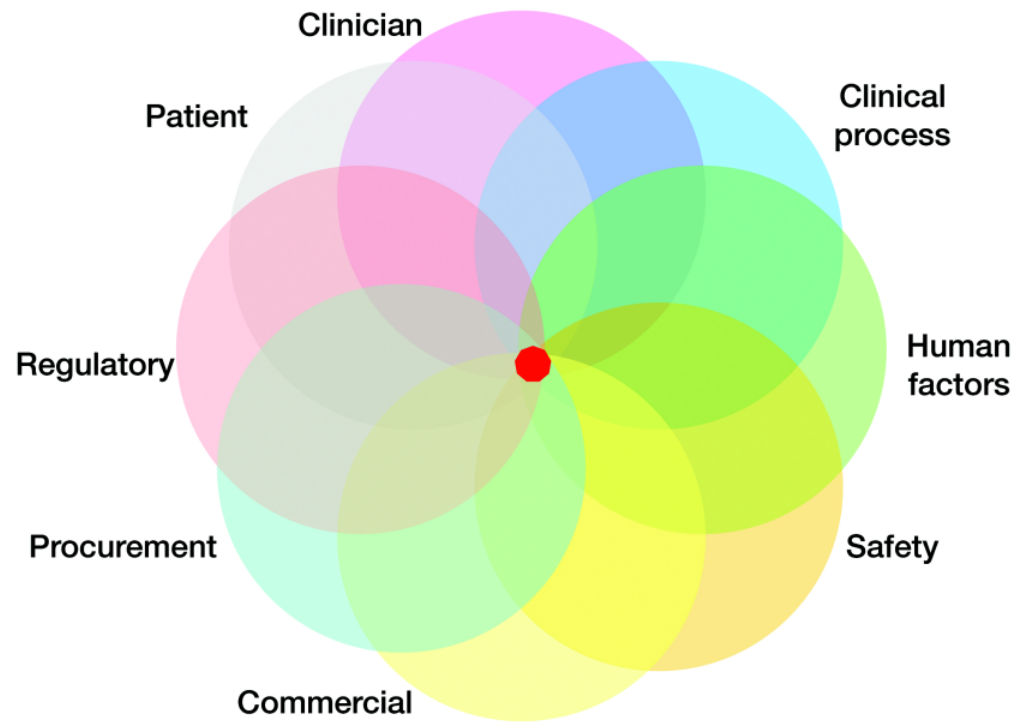


This added complexity may appear to overly constrain creative thinking, but confronting a broader spectrum of constraints early on in the design process could significantly improve the likelihood of eventual adoption. Returning to the example of the resuscitation trolley, a garment solution (e.g. dedicated team aprons stocked with resuscitation consumables) was one of the initial concepts. Had this been pursued further, the additional constraints of diagram 2 would have required an understanding of garment manufacturing constraints, the regulatory frameworks surrounding these, how such items are procured, and so on. The team instead pursued the trolley concept, which, despite early promise, failed to surmount key barriers to commercialisation. Scoping out downstream constraints for each nascent concept earlier on in the process could effectively limit the generation of designs to those with a good chance of succeeding, well before any significant investment in time and money, and is thus a much better use of resources.

\section{How do we embed downstream constraints earlier in the process?}

A straightforward answer may be to involve the downstream stakeholders earlier in innovation process. This is easier said than done. Apart from the practical difficulties of access to such stakeholders, there is the argument that constraint may inhibit important innovative thinking. Both sides of this argument may be viewed within the context of Stanford Biodesign's concept of superseding needs (Zenios, Makower, and Yock 2010) which effectively states that innovation efforts must be aware of where they are situated with respect to other innovation efforts.

Yock et al. illustrate the concept using the figure of a tree. Branch innovations may be superseded (or cut off the tree) by new trunk innovations. Their example focuses on atrial fibrillation, or irregular heart beating, which can cause blood clots which can have damaging consequences. A trunk innovation might help maintain a normal heartbeat; branch innovations might aim to prevent clotting. If the trunk innovation is successful, it reduces or eliminates the need for the branch innovation efforts. The point of the figure is not to say that trunk innovations are better than branch innovations, but rather to point out the risk of superseding needs.

Another viewpoint on this figure is to conceive of the tree as a set of design decisions. Fundamental concepts lie at the trunk level; embodiments, or design typologies form branches, and incremental improvements lie at the twig level.

From 2009 to 2015, the HHCD undertook a series of interconnected research and design projects related to the safety, quality and provision of emergency care (Harrow et al. 2009; Matthews et al. 2011). The research considered users and stakeholders across all levels of service provision, and some of the proposed interventions may be mapped onto the tree to illustrate this viewpoint (Figure 8).

Figure 8. Tree figure illustrating design decisions.

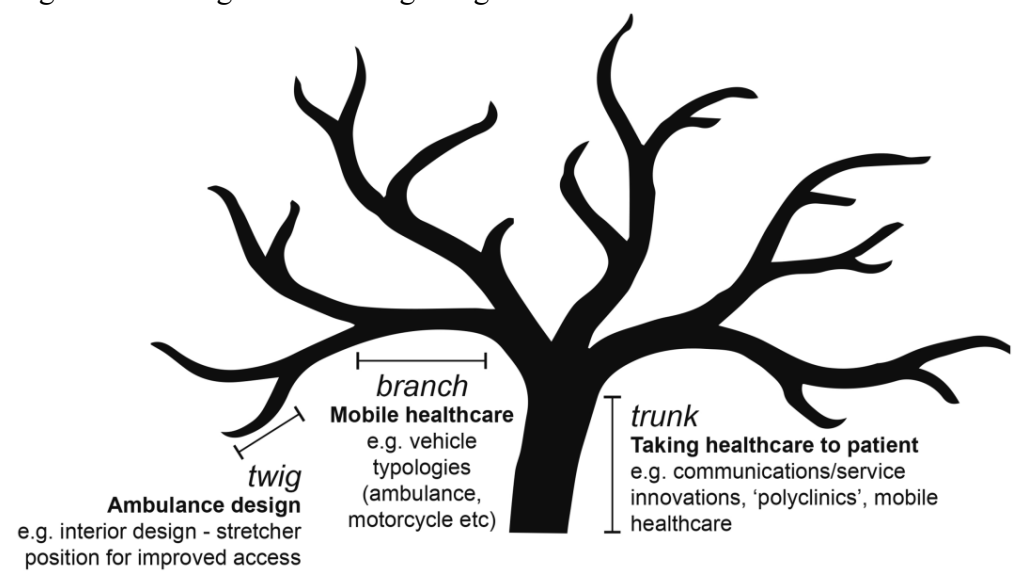

At the trunk level, more fundamental issues were considered. The aim was to take healthcare to the patient, and the areas considered (note that these are broad areas for innovation, not innovations per se) included communications (e.g. augmenting telemedicine), reconfiguring building and service provision of expertise (e.g. 'polyclinics'), or mobile healthcare. One the decision was made to focus on mobile healthcare, the branch level of decision then considers typologies, e.g. an ambulance, motorcycle, or potential new type of vehicle. Once the decision was made to focus on 
the ambulance, the twig level of design decisions considers the features, e.g. more intuitive and ergonomic equipment layout, or the positioning of the stretcher in the centre of the interior for improved access to the patient.

A further layer of meaning on this figure is provided if risk/investment/reward is considered. There may be twig design decisions involving small, incremental changes, with low risk of failure and relatively low level of investment. Branch decisions may be more ambitious, with higher risk, and trunk design decisions riskier still as they are likely to depend on fundamental scientific discovery and require industry and/or government funding at significant levels.

Procurement is necessarily based around the ultimate manifestations of the interventions once the designs are finished, i.e. it maps to the twigs. A whole new (and disruptive) type of intervention (trunk) would eventually be developed into a final product, variations of which would be new twigs. This would require completely new procurement channels. Importantly, incremental innovations may be procured through existing channels, which are notoriously resistant to change (Meehan, Ludbrook, and Mason 2016). It must be noted that efforts have been made to address the issues of procurement of new products and innovations, such as the NHS Innovation and Technology Payment (NHS 2019)

Returning to the example of improving emergency care, it would be wrong to expect a 'taking healthcare to the patient' project to deliver readily adoptable solutions, even when worked through the twig level. Such a new way of delivering healthcare, as envisaged in that project, would result in twig level solutions that are likely to sit outside current procurement practices.

There is also the important argument that much of the value of ambitious design projects lies not necessarily in translating innovations directly into front line practice, but in proposing visions for how things might be, and thus in opening up and invigorating debate. This argument shows the importance of clear goals in the design research project. A clear route to adoption might not be necessary in the case of more visionary projects. If, however, the goal $i s$ for design outputs to be adopted, it is vital that the position of procurement is understood, and that design efforts result in products that are a good fit with purchasing.

If innovations can be made at the same cost as existing products (and regulatorily compliant in the same manner), but with an added front line benefit, then the case for procurement should be self-evident, and adoption consequently easier. In this way, existing procurement lines could be used to get products adopted within tolerable cost constraints, but with numerous front line benefits once in use.

From the case studies and above workshop, it might be concluded that, in the context of front line initiated design projects, designers do not sufficiently understand the process of translation from testable prototype to widespread clinical use. Procurement must be involved and considered earlier, or indeed throughout, the design process. Procurement is at the level of finished product, and so twig-level design decisions are most likely to result in incremental innovations that might appeal to procurement. This would also serve as a means of initially involving procurement in the design process that may be hitherto unfamiliar.

\section{A way forward}

A potential model for optimising impact is to undertake a series of twig level innovation projects. These might be simple redesigns of existing products, giving a clear clinical and/or operational benefit with less risk and less investment. Importantly, this approach could be used in parallel with more ambitious 'branch' projects, thus achieving more immediate front line clinical benefit whilst the more challenging projects progress from concept to reality.

\section{Illustration}

One example of the type of innovation achievable by the model is the Flomark, a redesign of the hospital drip (or gravity administration intravenous (IV) set) (Figure 9).

Figure 9. Hospital drip, or gravity administration set. 


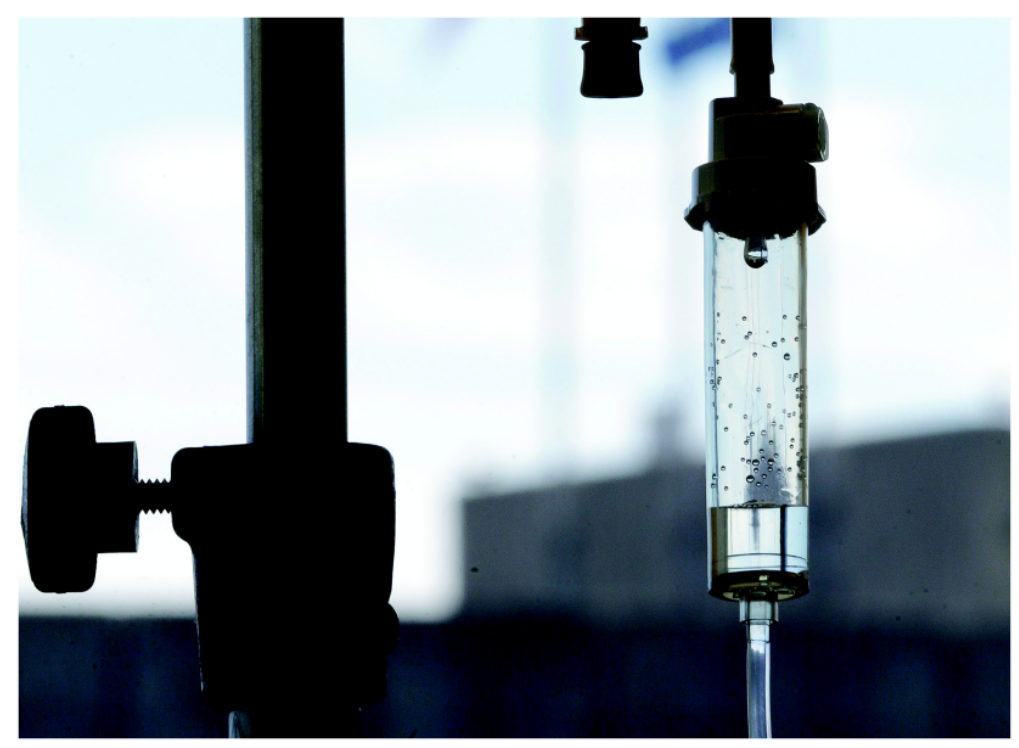

These are used to infuse fluids from a container into the patient, at a prescribed rate. This rate may be set using an electronic pump, or, more traditionally, by a thumb controller, with the nurse counting the drops falling through the drip chamber in the IV set. The literature is clear that compliance with drop counting is poor (Rooker and Gorard 2007), so the challenge was to redesign the IV set such that flow rate is easier to determine (Figure 10).

Figure 10. The Flomark - a redesign of the gravity administration set.

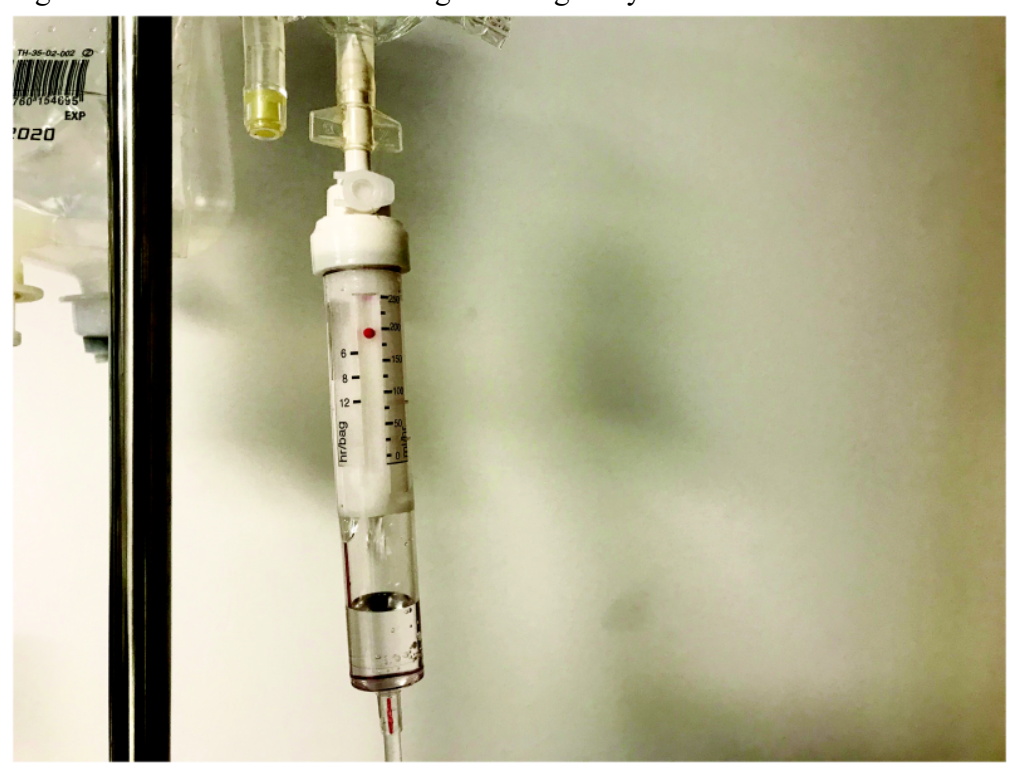

Cost and regulatory constraints were considered throughout the process. The redesign has the same part count as a standard IV set, but with an easy-to-read scale which has received unanimously positive feedback from the front line. The team are currently in discussions with a number of manufacturers interested in licencing this technology. If the unit costs are indeed identical to a standard IV set, the case for procurement should be relatively simple.

This model could be extended to other pressing clinical issues that lend themselves to a redesign. There is a growing body of knowledge about patient safety issues related to product/device design (e.g. Healthcare Safety Investigation Branch (HSIB) or the National Reporting and Learning System (NRLS)). Issues that are flagged up by the front 
line staff, or reports such as those generated by HSIB, could be used as starting points for such tightly defined design and innovation projects.

Designers are often tempted to view many products in the clinical environment as delivering poor user experience, and clinical frustration with such products gives weight to this view. However, an analysis of these products with regard to implementation considerations (cost, regulations, procurement procedures) would reveal that they are well designed from that perspective. The fact that these products successfully satisfy such downstream requirements effectively cements their place in the clinical environment, whereas radically different designs require clinical training, new procurement strategies, new manufacturing techniques and so on, all of which currently act as barriers to adoption.

However, such products and devices can be seen as conduits for innovation, as they are demonstrably a way of getting products into the hands of clinicians.

How can we use these conduits as a route to improving front line practice?

\section{Proposed methodology}

A proposed methodology:

1. Identify clinical/front line issues (e.g. via HSIB and NRLS)

2. Find existing products used within the relevant (or neighbouring) clinical/care processes to those identified in (1).

3. Inclusive redesign of products in (2), involving clinical users and implementation stakeholders.

4. Commercialisation, procurement (including payment and reimbursement), adoption, impact.

Change management is notoriously difficult. This methodology is intended to make change easier, as the generated outputs are intentionally similar to the status quo.

The methodology is scalable, ideally starting small, and gradually working at a bigger scale once it is refined. This is an important note on potential evolution of the methodology, as it is historically situated.

\section{A broader collaborative team}

This way of working requires a team which draws on all the above stakeholders. The collaboration between designers and front line stakeholders (clinicians, patients, ancillary staff etc) is well established. There is also precedent for involving industry (despite the above case studies, the HHCD team have successfully produced licenced products and commercial designs). Regulatory stakeholders are increasingly of the view that their expertise is of value earlier in the development process. A broader collaborative team which involves all of these members, and procurement, is necessary to address the challenge. Such a team might be difficult to assemble, and would require a clear focus and methodology to achieve early impact. This would start with simple innovations at the 'twig' level, above.

With this starting point, the team would learn each other's cultures and constraints, and build capabilities to address more ambitious or fundamental projects, at earlier design decisions, working the way down the tree to increase the scope of innovation, but at the same time being well versed in achieving impact.

The ultimate goal would be a team that understands the design and development process, and the process of adoption. Such a team would understand the position of an innovation on the tree, and source the necessary expertise to benefit its route to adoption. This would look very different for more fundamental innovations, positioned at branches and trunks, but would ideally speed up adoption of all (beneficial) innovation, as well as making it more likely to succeed.

The Design for Patient Safety report (Clarkson et al. 2004) made the case to involve procurement in the innovation process, along with clinicians, patients, designers and manufacturers. Although incident reporting data ensured a solid starting point for the above case studies, and good links were fostered between designers and clinicians which resulted in award winning designs, there was a lack of engagement with procurement. The importance of this was not fully recognised at the time, and the resulting difficulties in achieving impact lead to the central question: how might procurement be involved in the innovation process, in a way that builds lasting relationships? 
A broader collaborative team, following the proposed methodology could open up the possibility of a gradual movement from twig to branch innovations, and from incremental product redesigns towards higher and eventually system-level product/process improvements at the trunk level. This would feed back into the 'behaviour' and 'process' factors of patient safety as projects and collaborations gather momentum.

This broadening of approach also bolsters the case for adoption. Understanding cost effectiveness improves the credibility of the design process in the eyes of procurement, leading to further buy in, and ultimately a more widespread approach to cost accounting that includes the avoidable cost of clinical error.

\section{Conclusion}

The overall case being made is that although designers in healthcare now have unprecedented skills in user-centred design and co-design, there is insufficient early design engagement of other stakeholder groups critical for implementation and adoption. This results in exciting designs that may provoke discussion and have great front line feedback, but often lack the stamina, contacts and buy-in to make it into front line use, as the successful procurement of innovative design solutions is a considerable challenge. This may be minimised if design interventions that address clinical problems take the form of a redesign of an existing product, rather than a new type of device, and importantly match the cost of the existing product.

In this way the 'valley of death' described in many papers (Frank et al. 1996; Williams 2004; Meyer 2006) —-the stage at which many innovations fail on their way to commercialisation - may be avoided or reduced by putting tighter constraints on a brief, as described above.

The proposed approach would be a means of involving procurement in an innovation project without a great demand on resource as a first step towards a sustainable collaboration between clinicians, designers, procurement and other implementation stakeholders. Building a team around such clear and constrained design briefs that maximise the chances of successful adoption would foster ways of working together that could carry through to more ambitious projects. Importantly, such a team would be best positioned to conceive of solutions that fruitfully address the three factors necessary to improve patient safety_equipment, behaviour and process — by better engaging with stakeholders in the important and often neglected procurement chain.

\section{References}

Benger, J., and J. Blackham. 2009. "Why Do We Put Cervical Collars on Conscious Trauma Patients?” Scandinavian Journal of Trauma, Resuscitation and Emergency Medicine 17: 44. doi:10.1186/1757-7241-17-44.

Boyd Davis, S., and S. Gristwood. 2016. "The Structure of Design Processes: Ideal and Reality in Bruce Archer's 1968 Doctoral Thesis.” Design Research Society Conference 2016 Proceedings. doi:10.21606/drs.2016.240. [AQ1]

Coleman, R., J. Clarkson, H. Dong, and J. Cassim. 2007. Design for Inclusivity: A Practical Guide to Accessible, Innovative and User-Centred Design. Gower. [AQ2]

Coleman, R. 1994. The Case for Inclusive Design: An Overview, 12th Triennial Congress. International Ergonomics Association and the Human Factors Association of Canada, Toronto, Canada.

Clarkson, J., P. Buckle, R. Coleman, D. Stubbs, J. Ward, J. Jarrett, R. Lane, and J. Bound. 2004. Design for Patient Safety: A Scoping Study to Identify How the Effective Use of Design Could Help to Reduce Medical Accidents. Engineering Design Centre, Cambridge University.

Design Council 2015. “The double diamond.” Accessed 7 August 2019. http://www.designcouncil.org.uk/news-opinion/design-process-what-double-diamond

de Vries, E. N., M. A. Ramrattan, S. M. Smorenburg, D. J. Gouma, and M. A. Boermeester. 2008. "The Incidence and Nature of in-Hospital Adverse Events: A Systematic Review." Quality and Safety in Health Care 17 (3): $216-223$. doi:10.1136/qshc.2007.023622.

Frank, C., C. Sink, L. Mynatt, R. Rogers, and A. Rappazzo. 1996. "Surviving the "Valley of Death": A Comparative Analysis.” The Journal of Technology Transfer 21 (1-2): 61-69. doi:10.1007/BF02220308. 
Harrow, D., R. Coleman, E. Matthews, R. Thompson, D. Swann, S. Hignett, A. Jones, J. Benger, N. Caldwell, and A. Peterson. 2009. Healthcare on the Move: Treating Patients in the Community: The Smart Pods Project. London: Helen Hamlyn Centre.

Matthews, E., G. Fusari, D. Harrow, P. Stevens, R. Winsor, D. Dean, A. Darzi, and D. King. 2011. Redesigning the Emergency Ambulance. London: Helen Hamlyn Centre, Royal College of Art.

Meehan, J., M. N. Ludbrook, and C. J. Mason. 2016. "Collaborative Public Procurement: Institutional Explanations of Legitimised Resistance.” Journal of Purchasing and Supply Management 22 (3): 160-170. doi:10.1016/j.pursup.2016.03.002.

Meyer, R. 2006. The Start-Up Enterprise Valley of Death. Viewpoint, Capital Formation Institute.

Morris, Z. S., S. Wooding, and J. Grant. 2011. "The Answer is 17 Years, What is the Question: Understanding Time Lags in Translational Research.” Journal of the Royal Society of Medicine 104 (12): 510-520. doi:10.1258/ jrsm.2011.110180.

NHS. 2019. “Innovation and Technology Payment (ITP) 2019/20.” Accessed 22 November 2019. https:// www.england.nhs.uk/ourwork/innovation/innovation-and-technology-payment-itp-2019-20/

Rooker, J. C., and D. A. Gorard. 2007. "Errors of Intravenous Fluid Infusion Rates in Medical Inpatients." Clinical Medicine 7 (5): 482-485. doi:10.7861/clinmedicine.7-5-482.

Smyth, M., and M. W. Cooke. 2013. "Value of a Rigid Collar: In Need of More Research and Better Devices." Emergency Medicine Journal: EMJ 30 (6): 516. doi:10.1136/emermed-2012-201413.

Southampton University Hospitals NHS Trust. 2011. Showcase Hospitals Local Technology Review Report Timestrip $^{\circledR}$. The Showcase Hospitals Programme. Accessed 31 October 2019. https://assets.publishing.service.gov.uk/ government/uploads/system/uploads/attachment_data/file/216415/dh_130914.pdf

Sparke, A., K. Torlei, S. Voss, M. Page, J. Benger, E. Matthews, M. Hillman, et al. 2015. “The 'Necksafe' Head Articulation Control System: A Novel Cervical Immobilisation Device.” Emergency Medicine Journal 32 (7): 564-570. doi:10.1136/emermed-2013-203527.

Swayne, T. 2007. Design for Patient Safety: A Guide to the Graphic Design of Medication Packaging. London: National Patient Safety Agency.

University of Cambridge. 2017. Engineering Design Centre Inclusive Design Toolkit. Accessed 29 May 2020. http:// www.inclusivedesigntoolkit.com/aboutus/aboutus.html

Walker, S., A. McKay, N. Sevdalis, V. Deelchand, S. Lambden, S. Gautama, and C. Vincent. 2011a. "Assessment of a Newly Designed Resuscitation Trolley in a Simulated Environment.” Resuscitation 81 (2): S95. doi:10.1016/j.resuscitation.2010.09.387.

Walker, S., A. McKay, N. Sevdalis, V. Deelchand, S. Lambden, S. Gautama, and C. Vincent. 2011b. "Evaluation of the Effect of a Newly Designed Resuscitation Trolley on the Efficiency of the Cardiac Arrest Team in a Simulated Environment." Anaesthesia 81 (2): 959-960. doi:10.1016/j.resuscitation.2010.09.387.

West, J., S. Halls, R. Coleman, and C. Lowe. 2008. "Resus:station: Breathing Life Back into Resuscitation.” Improving Patient Safety Conference Proceedings, Cambridge, July 15-18.

Williams, E. 2004. “Crossing the Valley of Death.” Warwick Ventures, University of Warwick. Accessed 6 November 2019. http://www2.warwick.ac.uk/services/ventures/valley.pdf

Zenios, S., J. Makower, and P. Yock. 2010. “Observation and Problem Identification.” In BioDesign: The Process of Innovating Medical Technologies, 45-46. Cambridge University Press. [AQ3]

\section{AUthor QUeries}


Query: AQ0: Please review the table of contributors below and confirm that the first and last names are structured correctly and that the authors are listed in the correct order of contribution. This check is to ensure that your names will appear correctly online and when the article is indexed.

\section{Sequence Prefix Given name(s) Surname Suffix}

1 Jonathan West

\section{Author Response: Ok}

Query: AQ1: Please provide the location for "Boyd Davis and Gristwood 2016".

Author Response: Brighton, UK

Query: AQ2: Please provide the publisher location for "Coleman et al. 2007".

Author Response: UK

Query: AQ3: Please provide the publisher location "Zenios et al. 2010".

Author Response: Cambridge

Query: AQ4: Please note that the ORCID section has been created from information supplied with your manuscript submission/CATS. Please correct if this is inaccurate.

Author Response: Ok 